\title{
What am I 'living' with? Growing up with HIV in Uganda and Zimbabwe
}

\section{Sarah Bernays ${ }^{1}$, Janet Seeley ${ }^{2}$, Tim Rhodes ${ }^{1}$ and Zivai Mupambireyi ${ }^{3}$}

\author{
${ }^{1}$ London School of Hygiene and Tropical Medicine \\ ${ }^{2}$ London School of Hygiene and Tropical Medicine and MRC/UVRI Uganda Research Unit on \\ AIDS \\ ${ }^{3}$ Centre for Sexual Health and HIV/AIDS Research, Zimbabwe and University College, \\ London
}

\begin{abstract}
As paediatric HIV treatment has become increasingly available across the world, the global perinatally infected cohort is ageing. However, we know surprisingly little about what it is like to grow up with HIV in resource-stretched settings. We draw on findings from a prospective, qualitative study with HIV-positive children, their carers and healthcare workers from four clinics in Uganda and Zimbabwe to examine children's experiences of living with HIV on treatment. We consider how the HIV experience is made in a symbiotic relationship between children, carers and healthcare workers and shaped by broader discourses. Despite the radical development in prognosis for children, their experience of HIV is largely constructed in relation to a language of 'sickness' through the promotion of medicalised talk and the recounting of past illness stories. This narrow narrative framework both reflects and reproduces core dimensions of the lived experience of growing up with HIV, which emphasises an absence of resilient healthiness in the face of ongoing vulnerability and risk. The challenges that children encounter in articulating alternative narratives that prioritise the relative buoyancy of their health is indicative of the broader uncertainty that exists around the future for these children at this point in the epidemic.
\end{abstract}

Keywords: HIV/AIDS, children, sub-Saharan Africa, narratives, chronic illness

\section{Introduction}

Enormous progress has been made in the efficacy of treating children born with HIV. Perinatally infected children can now lead long, productive lives, providing that they have continuous access to anti-retroviral treatment (ART) (Busza et al. 2013, Heymann et al. 2008). In high-income settings the almost complete success in reducing mother-to-child transmission means that paediatric HIV has now become an adolescent epidemic, with those already infected surviving into adulthood (UNAIDS 2012). Yet we know surprisingly little about what it is like to grow up with HIV and ART, especially in sub-Saharan Africa where almost all $(91 \%)$ of the estimated 3.4 million HIV-positive children live (World Health Organization 
2013). Despite the impressive clinical progress in improving survival rates and life expectancy, children's lives continue to be characterised by substantial biomedical and social uncertainties (Domek 2006). In our article we draw on the accounts of perinatally infected children aged 11-13 years old, living in Uganda and Zimbabwe, as well as those of their carers and healthcare workers. We examine the children's experiences of living with HIV on ART, where HIV is relatively common and yet these experiences are also silenced, as well as surrounded by uncertainty. We aim to describe how children articulate 'living with' and 'growing up' with HIV and how this is shaped through their relationships with the adults around them.

\section{Background}

The potentially transformative effects of ART on HIV have been well documented (Campbell et al. 2011, Castro and Farmer 2005). In both high-income and low-income settings there have been radical changes in the illness narratives of people living with HIV, characterised by narratives of disruption and shattered lives in the time before ART, to narratives of readjustment and restoration post-ART (Davies 1997, Robins 2005). ART is popularly represented globally by a collective narrative of enabling a return to normal life by having turned HIV into a manageable chronic illness (Russell and Seeley 2010, Wouters 2012).

Yet studies also contest the linearity of the post-ART experience, noting that clinical recovery can lead to a mixed array of emotions and social outcomes (Seeley and Russell 2010), as has been shown with other illnesses (Shapiro et al. 1997). The rhetoric surrounding the global scale-up of ART has been very promising; however this conceals the significant variation in the lived experiences of treatment and its social effects, including between individuals, across settings, and over the course of the illness trajectory (Goudge et al. 2009, Seeley and Russell 2010, Wekesa and Coast 2013). Importantly, the relationship between treatment uptake and the decline in the stigma of HIV is not universal (Abrahams and Jewkes 2012, Bernays et al. 2010, Maughan-Brown 2010). The need or desire to maintain a pragmatic silence in relation to HIV continues to persist in many settings and this not only threatens the capacity to engage with ART (Bond 2010), but suggests that the process of normalising HIV through ART is socially complex, slow and uneven (Bernays et al. 2010, Gilbert and Walker 2009).

\section{Understanding children's HIV treatment experiences}

Two core overlapping concepts that have been influential in understanding individuals' responses to chronic illness, including HIV, are biographical reinforcement, characterised by an individual born with a chronic condition facing life disrupted by 'socially-set standards and cultural prescriptions of normality' (Williams, 2000: 50) and transition, characterised by an active adaptation towards incorporating illness and its treatment into daily life and identity (Russell and Seeley 2010). Children born with HIV, who have started ART at an early age, have no experience of life pre-HIV to use as a reference point or embodied knowledge of normalcy without illness. Rather, these children's remembered normative experiences are more likely to revolve around the illness experience and the taking of HIV treatment. Their experience of biographical reinforcement may be most particularly felt through changing life circumstances brought about, for example, through the death of a parent and having to negotiate new care, home and school environments (Daniel et al. 2007). Children's experience of growing up with HIV and ART may, to some extent, be articulated as a form of social rebirth (Seeley and Russell 2010), in keeping with a narrative of transition, for ART may afford novel social opportunities associated with good health and positive interaction with peers. Yet despite ART, children's social lives may be hindered by the irreversible visual markers of HIV, such 
as scars resulting from skin disease or stunted growth, leaving them noticeably smaller than their peers.

Despite the vast numbers of children infected and affected by HIV in sub-Saharan Africa, documenting the effect of the HIV epidemic on children has been neglected (Skovdal et al. 2013). Firstly, there has been a tendency for studies to focus on the experience of children and young people in high-income and low-prevalence settings (Mellins and Malee 2013). While the findings from research in industrialised settings may have some relevance for children living in sub-Saharan Africa, such as the role of silence in managing perinatal HIV (Fielden et al. 2011), the vast clinical, social, material and epidemiological variations between (as well as within) these contexts are likely to shape HIV experiences differently. Secondly, there has been a methodological and ethical preference for research to focus on the adults in children's lives as proxy representations of their experiences. The primary exception to this is the research that has been done with young carers, where the agentic capacity of children has been more readily recognised (Andersen 2012, Evans and Becker 2009, Skovdal et al. 2009). This research blind spot in part reflects the history of the availability of global paediatric HIV treatment and the relative novelty of this surviving cohort, as well as the highly sensitive and relational nature of paediatric HIV as an illness, but it also demonstrates a generalised regional and disciplinary trend in which researchers have been slow to embrace the role of children in research.

\section{Researching children's narratives of HIV experience}

The once hegemonic conceptualisation of children as passive, developing and 'unfinished' persons is a relatively outdated idea in the sociological literature (Prout and James 1990). However, its effect on research design in studies with children has been far-reaching, with researchers tending to position children as objects of research rather than participants in the process (Kirk 2007). Theorists increasingly cast children as competent contributors to social life; a social competence achieved through living in the world (Prout 2000). But empirical studies show that this is bounded by specific contexts, the various structural and relational features shaping their lives and their biological vulnerabilities as well as the extent of their experience (Berman 2000, Hutchby and Moran-Ellis 1998).

Given this relational complexity, we explore children's lived experience of growing up with HIV through the narratives that they and the adults around them tell about their lives and the role of HIV within them. Cognisant of the debate around the privileging of narrative methods in illness contexts (Thomas 2013), we do not consider these narratives to be transparent, hyper-authentic representations of experience. Rather, analysing these narratives becomes an opportunity to illuminate how experience is represented through a process in which power is contested and negotiated (Mazanderani et al. 2013). Our consideration of narratives involves examining the broader context in which stories are told, attentive to the socially constructed and performative nature of how illness experience is represented in interview accounts. This is revealing about wider social and economic conditions, as well as more localised processes, values and norms that frame which narratives come to dominate and shape the accepted representations of illness experience (Mishler 2005). Furthermore, narratives can be a means to understand the evolution of an illness and the fluid evaluation of an individual's past and future in light of changing circumstances (Ochs and Capps 1996).

The consideration of these concerns has important theoretical implications for how we recognise and understand narrative resistance and subsequently the evolution of illness narratives. Children's narratives may be subsumed or shaped by those of adults (Bluebond-Langner 1978), who themselves are informed by and interpret the language and narratives about HIV that circulate within their broader community. But whether alternative accounts are recognised 
as resistant narratives may rely on the capacity to be heard, which relies in part on their access to language in order to hold a recognised perspective, as well as the willingness of the audience to listen (Pols 2005). This feeds into our understanding of the evolution of narratives as illnesses and societies change and the pace at which these revised versions are accepted as being legitimate, making it increasingly difficult to separate out the individual from the collective experience, as neither exist in a vacuum but are inextricably connected.

Given the link between collective and individual experience and power, our purpose is to consider how the narratives of children, which may be significantly shaped by the stories available to them, and their experience of growing up with HIV affect their capacity to represent alternative experiences. Specifically, we examine how perceptions of children's wellbeing, health and illness engage with and manage the dialectic of hope and uncertainty inherent in paediatric HIV at this point in the epidemic.

\section{Methods}

\section{Study design}

We draw on findings from a prospective, qualitative study (2011-2013) conducted with children aged 11-13 years old perinatally infected with HIV across three sites in Uganda and one in Zimbabwe. We conducted 104 baseline in-depth interviews and then followed up 60 of these children for 16 months through two further in-depth interviews (15 per site) and in the Zimbabwe site 12 out of 15 of these children also kept an audio diary. Twenty of the children from the baseline sample participated in three focus groups (FGDs) in Uganda and Zimbabwe at the end of the data collection period.

Our approach is influenced by the theoretical framework of bounded agency, which focuses on the influence of structure, while allowing space for individual agency, in constructing an individual's experiences (Evans and Becker 2007). Specifically, our study includes separate interviews with 40 adult carers (10 per site) and 20 healthcare workers in the clinic (5 per site) because we are interested in the relational influences in children's lives that contribute to framing and shaping their experiences. This inclusion gives a fuller picture of the children's experiences by recognising how children's personhood and agency are shaped by intergenerational relationships (Evans and Becker 2009).

All the children were participating in the Anti-Retroviral Research for Watoto clinical trial (ARROW), from 2007 to 2012. It was conducted with 1200 children aged 6 months to 14 years. Participants began HIV treatment at enrolment and the trial assessed two different management strategies for giving first line anti-HIV drugs (ARROW Trial team et al. 2013). While the trial interventions were not a focus of the qualitative study's investigation the trial acted as a recruitment pool for the qualitative study sample. We focused on children aged 11-13 years both because they have been especially neglected in research and to explore the interim period post-disclosure, which in both Uganda and Zimbabwe is encouraged from the age of 8 , and prior to them becoming a focus for HIV prevention and sexual health initiatives.

\section{Sampling}

Of the 104 children involved at baseline there were 58 girls and all participants were distributed across the age-range. To be included they had to have been aware of their HIV diagnosis for at least 6 months. The baseline sample from each site represented a significant proportion of those eligible for inclusion. We then followed a reduced sample of 15 from each site for two further interviews $(n=60)$. We adopted a theoretical sampling strategy informed by the findings of the baseline, having identified orphanhood status and knowledge of perinatal 
transmission as important characteristics shaping their experiences. In the follow-up sample there were 25 boys and 35 girls, reflecting the trial sample among this age group. They were evenly spread across the age range, with 19 participants aged 11, 21 aged 12 and 20 aged 13 years. Of this sample of 60 children, 22 were double orphans, 32 had lost either their father or their mother and only six had both parents alive. Fifteen of the children in the sample did not know about perinatal transmission. The 20 healthcare workers who were invited to participate were selected because they all had high levels of contact with the children in the clinics. They included doctors, nurses, counsellors and pharmacists. Of the 40 carers who were interviewed, 23 were parents of the children, 15 were other biological relatives and two were nonbiologically related carers. Seventeen of these carers were themselves HIV-positive, with five others reporting that they were HIV negative and the status of the remaining 18 was unknown.

\section{Data collection and analysis}

Most of the interviews took place in private rooms at the clinics and involved just the participant and the local interviewer. The interviews were semi-structured, shaped by the relevant topic guide, and were tailored to the individual. Being encouraged to talk about HIV and asked for their opinion by an adult were relatively novel experiences for most of the children. However, our task-based approach alongside the repeat interview design, in which children met with the same interviewer each time, enabled rapport to develop and children reported growing in confidence to talk as the study progressed.

Ethical approval was provided by all the appropriate committees in Uganda and Zimbabwe, as well as the London School of Hygiene and Tropical Medicine. All data were collected with the participants' written informed consent. For the children's interviews this involved the informed consent of their carer (parent or guardian) and the assent of the child. Interviews lasted between 30-120 minutes and were primarily participant-led. Participants received a transport refund and refreshments for each interview, and those participating in the FGD also received a t-shirt. All interviews and FDG were tape recorded and conducted in the language of the participant's choice (Luganda, Shona or English). Data were transcribed verbatim, translated for equivalent meaning and checked by the interviewer. We approached translation as both a technical and discursive process and discussions were held within the team during both the initial translation process and through the analysis to ensure that the complexity of concepts was conveyed.

Data collection and analysis were conducted iteratively, informing each subsequent phase of data collection. We used a combined thematic and narrative analytical approach. Initially, we compiled case summaries, amalgamating interview and field-note data for each participant. Carer interview data were included in the summaries for the related child, with particular attention being paid, through the drafting of extensive analytical memos, to relationship dynamics and points of congruence and diversion between the adults and children's accounts.

We managed the thematic coding of the full dataset into primary and detailed subthemes using NVivo 8. Our narrative approach involved paying attention to whether particular stories were repeated across the interview transcripts. We considered whether there was a narrative similarity across the accounts, in terms of there being common ideas and patterns in how, for example, the children described their experiences and whether this differed from those of the adults. This enabled us to identify both the personal narratives, which were the stories that participants gave to describe their own experiences, and the broader, cultural narratives about HIV, which they were responding to in their accounts to contextualise their own experiences and structure how they made sense of HIV in their everyday lives. Through this approach we identified a dominant narrative about children growing up with HIV that appeared to 
encapsulate the current common representation of the illness experience, and an alternative narrative, in which children themselves engaged with and contested this dominant narrative. All names used are fictitious.

\section{Findings}

\section{Constructing HIV through a language of sickness}

We found that children's experience of HIV is largely constructed in relation to a language of sickness. Although all the children involved in the study were themselves on ART and most were relatively healthy, almost without exception they associated HIV with illness and weakness. The children described people living with HIV as being visibly ill and depicting them as 'thin and small', sometimes physically short, with 'scars and wounds all over their bodies', as someone who 'doesn't want to eat' and has 'thinning hair'. It was only with prompting that they mentioned people on HIV treatment. The children's accounts were littered with horror stories about the physical appearance of other people living with HIV, 'even your hair becomes brownish and it drops out when you comb it like a cancer patient' (FGD). This was not just a question of being identified as HIV positive through signs of poor health but also a consequence of ideas about HIV positivity that ignored the relatively stable health that someone on ART might enjoy.

\section{Let me be normal}

Despite this characterisation many children did not consider themselves to be sick, describing themselves instead as being strong and appearing healthy. This created a tension. Given the dominant imaging of people living with HIV, they struggled to recognise themselves within this picture of 'sickness', as Anita (aged 12) describes: 'Ha! I wasn't worried about an illness that maybe I have HIV ... I wasn't worried and I never counted myself among those that have it!'

However, in spite of the disassociation children made between their own state of health and those of other 'sick' people living with HIV, many carers continued to emphasise their child's vulnerability and propensity to sickness. Many children were singled out by their carers as being weaker than the other children in the household because they 'are sick' and required 'special care'. Job's grandmother, for example, insists that he carries a smaller amount of water than other children because of the fear that 'his body may weaken a bit'.

However, Job (13 years old) does not consider himself weaker than the others and asks to be allowed to do the same as the other children, saying: 'I think I am fine'. The challenges that Job has in resisting the restrictive parameters his grandmother imposes, regardless of his opinion, is indicative of the struggle that children encounter in trying to shape and define their own experience of living with HIV. So, while at an individual level the children, like Job, might perceive themselves to be 'healthy', in this social context at the level of the household and broader community they are defined through an association with sickness that inextricably accompanies their HIV status.

All the children, in describing the impact of HIV on their own appearance, emphasised that a valuable effect of ART lay in its capacity to render HIV virtually invisible, whereas prior to ART it had been obvious on their bodies and many children had been teased and ostracised as a result. The children invested heavily in concealing and disguising their HIV status in order to be indistinguishable from their peers and considered normal. The value of ART was in the opportunity that it gave to maintain this impression of normalcy, rather than in enabling someone to become healthy. This appearance of normalcy was precarious and constantly vulnerable 
to disruption, not only by the telltale physical indicators of previous illnesses but the activities accompanying continuous adherence to treatment, such as having to leave school every day at a certain time to take their pills and the special treatment they received from adults. If the children could successfully negotiate these risks and continue to maintain an appearance of normalcy some sense of well-being was achieved. However, this was firmly located in a denial of illness rather than an attainment of health.

\section{Boundaries of HIV talk}

Despite the difference in priorities noted between some adults and children, there was a general consensus that children's HIV should be managed in relative silence. Once the diagnosis had been disclosed, HIV was rarely talked about in the household and the children were discouraged from discussing it with anyone else. We identified two exceptions to this pattern of silence: medicalised talk and past illness stories.

\section{Medicalised talk}

Post-disclosure, even outside the clinic, HIV was communicated almost exclusively through discussions about the symptoms of illness and HIV medicines, such as adherence reminders about treatment and clinic appointments. Mary (12 years old) describes how her aunt consistently reminded her of the precariousness of her health: 'If you do not take drugs you fall sick and die'. There was little to no discussion of the ways in which HIV influenced and shaped their social lives and the role that HIV may play in the future. For example, although many children had been disclosed to by their primary carer, the experience of Samuella (11 years old), who said that she had 'not spoken about it with Daddy since then', was very common. On the rare occasion when the children did break the silence to initiate discussion about HIV, for example to ask how long they had to take drugs or their futures, often their questions went unanswered or were dismissed as being unnecessary and the children were discouraged from 'thinking too much'. Charity (13 years old) would take herself away from everyone when she thought about HIV and explained that 'each time I recover from having deep thoughts I pretend to have forgotten about it and I will join others and laugh with them'. Martha (12 years old) used to ask many questions about HIV, such as 'Why am I like this? Why am I HIV positive?' She, like many other children, was strongly discouraged from voicing her questions and anxieties about growing up with HIV. Martha's cousin explained how 'no one brings up such conversations' and surmises that 'she now doesn't think a lot about it because no one tells her such things any more'.

\section{Past illness stories}

We identified one other exceptional circumstance in which HIV was talked about. This was the selective rehearsal of past illness narratives in which children and their carers recounted the child's particular illness story prior to treatment initiation. Charity (13 years old), in common with many of the children, describes her past illness in vivid, embodied terms:

When we went [to hospital] for the second time I could not breathe properly and I told my mother that I was failing to breathe ... She called the nurses and I was put on oxygen. Then I started to breathe well. So each time I think of it I will say 'I could have been dead by now and there would be no one by the name Charity'.

Whether experiences were reported or remembered, they formed a pivotal feature of the children's memory of the past and were central in defining their present experiences. 
The narrative pattern in both children and carers' accounts follows a dominant structure in which talk about their experience of living with HIV is divided into 'then' (ill, weak, hospitalised, small) and 'now' (on ART, stronger, healthier, looking normal). Isaiah's aunt recalls his situation prior to starting ART and how he reflects on the difference between then and now:

The thing was, he was continuously sick, in bed and there was a time he was unconscious and they told people he had passed away. In fact, when you ask Isaiah, he still remembers that incident and at times he tells me that, 'Mum, one time my granny told people I was dead because she thought I was about to die but can you imagine that I am alive!' If you asked him about that time he can tell it to you because by the time I picked him from that place his brain was working fine and he could understand what was going on.

It is striking that these stories can be told in some detail by the children and the carers even though they generally occurred at least 3 years beforehand, prior to starting in the ARROW trial. However, when asked how they were disclosed to, which is likely to have been more recently, the children commonly say that they cannot remember. This suggests that these illness stories are more likely to have been retold and reinforced in their memory.

\section{Silencing talk of non-adherence and the future}

In considering why the retelling of illness stories, between the carer and the child, is legitimate and encouraged it becomes clear that they are used to motivate continued adherence. The threat that 'you'll be sick again, like you were before' is used to scare the children into maintaining adherence.

There were many reasons why maintaining adherence was challenging, including managing the side effects, which were exacerbated by household food insecurity; protecting against disclosure by being identified as taking treatment; feeling tired or overwhelmed by the relentless, daily doses; or forgetting. Children expressed their frustration at the lack of sympathy that they received when struggling to take treatment every day and how they felt that adults commonly dismissed the broader psycho-social reasons that underpinned instances of non-adherence. As Jacob (11 years old) says: 'When they hear they call you stupid and think that you are lying to them ... because for them they don't take it'.

Children described times when they had felt like not taking treatment any more or stopping; although they said that they rarely acted on it. When asked why or how they had managed to resist these inclinations they responded by using their illness stories to illustrate how bad it had been when they had not taken their drugs. As Charity (13 years old) explains, 'I take my pills every day and I don't skip them because when I was sick each time I think of it I feel like crying'. The sense of fear surrounding the ongoing risk and the imperative of avoiding the past is also voiced by some of the healthcare workers when counselling a child once an adherence problem is identified:

You try to remind them [the child] how they were when they came to ARROW. Then they will say 'I was not going to school', 'I was not able to do this and that' and you will ask them if they want to go back to the same situation.

These forms of HIV talk may inadvertently dismiss or fail to engage with the social challenges children face in sustaining their adherence. Furthermore, the children reported that if they did miss treatment they were unlikely to tell anyone about it because, 'I'll be scolded or beaten'. They had learnt to edit out the features of their experience that are not well-received and do not fit within the dominant representation of their experience. In turn, the silence that exists 
around non-adherence further feeds and shapes the dominant script around growing up with HIV on ART.

Although these narratives appear to play a valuable role in making sense of the past and present, the future is rarely mentioned. Children are told 'not to think about it'. When the future is discussed, though, it is in uncertain, anxious terms. While carers hoped that their children would grow up to lead 'normal lives', a number of them expressed concern about the exceptional 'burden' that these children carry in growing up with HIV in relation to risk and limited opportunity, especially about their future sexual and reproductive lives. Jovia's brother compares his life, growing up HIV negative, and his sister's:

I started enjoying myself a long time ago and if they discovered HIV now and I start drugs, at least I will have moved and have done what I have done. But the child will never enjoy herself ... So you will find that all her life that she will be in danger; you have removed that [free sexual] act from her and even if she becomes an adult, she will go for it fearfully ... She has not any hope.

These rare spaces for selective discussion about HIV, medicalised talk, illness narratives and the interviews themselves, all converge to form a script around the experience of perinatal HIV, which emphasises that their current position is threatened by an absence of resilient health. The relevance of these memories as a way of 'knowing' about HIV may be particularly important when their knowledge of HIV and the management of HIV in other forms are limited.

\section{Children's protest talk: 'but I am not sick'}

While the children's interpretation of their illness experiences does appear to be heavily influenced by the talk both around and readily available to them, there are instances in which they contest this characterisation of their health. Crucially, both the medicalised talk and past illness stories described above are led by adults and are legitimised as acceptable forms of discussion about the child's HIV. However there is one additional, but rare, form of talk adopted by the children alone, which we characterise as protest talk.

Although the language used by the children appears to percolate into how children articulate their conditions, in describing themselves as sick, there are times when children are quick to follow this statement by emphasising, 'but I feel fine'; 'but I am strong'. These limited, but common, expressions allude to the complexity of their lived experience in being at once described as sick but feeling well. For example, having spoken about the visible indicators of illness displayed by people living with HIV, Rose (13 years old) describes her own appearance quite differently: 'I'm well, nice looking and beautiful. I have no scars, I'm not sick'. Unlike the more negative tone of the carers, when discussing her future aspirations, she explains how she thinks about the future: 'I told myself, on the earth there is no one who will never die, even that one who is not sick dies, and yet you who have HIV you remain alive'. Similarly, Grace (13 years old) asserts her sense of health, explaining that she does not perceive that HIV limits her opportunities or capacity: 'I am just a happy person because there is nothing that I cannot do; I can do all the chores. I can do everything. . . I am healthy and look strong'.

Rudo (12 years old) encourages other HIV-positive children to avoid being presumed to be sick by trying to participate in everything:

It's better for people to be taken by surprise to say 'Ah, this child may be thin and we were thinking that she is sick but she is very hardworking'. But on your own you will know that you are on pills and the pills are making you strong and have the energy. 
While such positive talk, which protested against the normative characterisation of their experience, was present in children's accounts it was in subtle forms and only occasionally articulated. Most commonly it was silenced within everyday talk. For example, Job (13 years old) had not told his grandmother that he felt able to carry the same amount water as the other children his age. Where it is articulated, though, this may indicate the embryonic forming of resistance narratives, in that they contest the normative characterisation. This narrative does not deny the challenges inherent in living with HIV but instead aims to prioritise the opportunities for health and well-being brought by living well on ART.

\section{Discussion}

We have noted that the lived experiences of children have been constructed through the symbiotic relationships between children, their carers and healthcare workers and the broader discourses through which these individuals are influenced. This relational complexity shapes how children consider and articulate what it is like to grow up with HIV. However, the capacity these three groups have to shape their accounts is not equal but, rather, filtered through a prism that reflects the distribution and negotiation of power between the parties involved (Mazanderani, Locock, and Powell 2013). This can be seen by how talk outside the medical frame is inadvertently shut down, with children discouraged from talking or even thinking about HIV in their everyday lives. This serves to frame the experience of HIV as singularly biomedically felt and embodied, often ignoring the social effects (Waitzkin 1991). Such edited talk, with silence indicative of disquiet about the social implications, suggests that 'living with' and 'growing up with' HIV continues to be imbued with social uncertainty.

This limits children's autonomy to articulate their experience along alternative lines as their sense-making is narrowed by the narrative grids available to them to frame their experiences (Wilkinson 1988). However, this is contested to some degree through the presence of protest talk as well as silences, but recognising its subtle manifestations depends on our capacity to notice such talk (Hendry and Watson 2001). Notably, this emerging alternative narrative appears to have little influence on how adults recount children's experiences. Instead the adults' emphasis on these children's ongoing vulnerability to sickness reinforces their biographical status as different from other children. This illustrates the inherent challenges that children face in achieving a sense of normalcy when growing up with HIV, despite the apparent invisibility of HIV when it is successfully controlled by treatment; and is indicative of the limited nature of their transition from illness to health. Our analysis illuminates the effect of bounded agency on children's articulation and experience of living with HIV, as it is through the exploration of this relational complexity that we can observe the influences which shape their narratives.

\section{Silence and illness stories as disciplinary}

The HIV experience script that is created does not just reflect how adults may narrow the articulations of children directly, but illustrates how children also engage with and interpret the narrative frameworks that define what constitutes acceptable talk. Children learn to edit adherence slippages and problems out of their reported treatment experience. Taking a Foucauldian perspective, this form of silencing not only highlights the importance of examining how power is operationalised through who is, and who is not, allowed to speak, but also in considering which subjects are silenced. Children may see that silence on the subject of non-adherence is a tool for their social and cultural survival (Fielden et al. 2011). This silence, if ignored or not heard, appears to strategically accommodate and reproduce the dominant narrative, which 
neglects the prominence that social concerns may play in conditioning the experience of growing up with HIV. This, in turn, limits the opportunities that there may be to diverge from the accepted script and articulate alternative narratives,

The illness narratives told by carers and children form a central organising thread in the representations of the children's experience. The accepted structure of this narrative, told through multiple discourses, pivots around HIV pre-ART and the rejuvenating effects of the successful initiation of treatment. The hopes generated by ART are illustrated and consolidated by the telling of these past illness stories. This may also function, in part, as a moralising discourse to engender ongoing discipline and commitment to adherence, as well as, by extension, to become a stratagem of blame for non-adherence. Furthermore, in discrediting talk of non-adherence, this dominant narrative may also serve to resist the unwelcome and disquieting narrative that articulates how, despite the opportunities brought about by ART availability, its long-term efficacy may be disrupted by the social challenges that accompany long-term adherence to ART. Together, these patterns of talk act in the service of a medicalised HIV identity, which silences alternatives and, in ignoring these social challenges, neglects these children's desires to focus on appearing normal as a means to achieving a sense of well-being.

\section{Challenges to realising normalcy}

We have shown how illness narratives and medicalised talk firmly assert the language of sickness within the characterisation of these children's experiences. This undermines a quest for ordinariness (Kralik 2002), in which the opportunity to diminish the centrality of their HIV diagnosis in their lives is made more difficult by the prominence given to illness events in shaping their present narratives. Although ART renders the illness virtually invisible, talk around treatment appears to reinforce the presence rather than alleviation of this 'sickness' (Hunleth 2013, Williams 2000) and, as such, who/what risk becoming fixed as commensurable and inextricable (Ezekiel et al. 2009). Ironically, perpetuating HIV's association with the discrediting attributes of sickness exacerbates the social challenges people encounter in maintaining exemplary long-term adherence and benefitting from the clinical opportunities afforded by ART.

The focus on the certainty of the past and the absence of a script to articulate the everyday realities of long-term HIV treatment in the present may indicate the doubt that circulates about the future for these children as they grow up with HIV. Therefore, the linguistic tension in their protest talk and the challenges that children encounter in articulating the relative buoyancy of their health may be indicative of the broader struggle to negotiate what the present and future looks like and means for individuals growing up with HIV, their households and the healthcare sector. Setting which are characterised by burgeoning but precarious access to ART, high levels of orphaning and the stretched resources that are available to meet the potentially complex needs of these children.

However, that there is protest talk at all suggests the presence of some embryonic resistance to this dominant narrative, which attempts to contest the equivalence attributed to being HIV positive on ART and being considered 'sick'. Through this, some children describe how living with HIV under these conditions involves living in a liminal state in which apparent binaries, such as health and sickness, strength and weakness and invisibility and spoilt identity, exist in an everyday tension. The presence of protest talk and the opportunities afforded by ART, if access is secure and households are given adequate adherence support, suggests that children would benefit from a shift in focus towards looking at how to foster and maintain resilience (Kia-Keating et al. 2011, Luthar et al. 2006). Emphasising the possibilities that are available to those growing up with HIV on ART, rather than the more singular focus on them as 'at 
risk' to themselves and others (Busza et al. 2013, Mellins and Malee, 2013), may alter the current vocabulary used to describe this population and contribute to accelerating the development of alternative narratives that reflect children's experiences of growing up with HIV.

Address for correspondence: Sarah Bernays, Public Health and Policy, London School of Hygiene and Tropical Medicine, 15-17 Tavistock Place, London WC1H 9SH, UK.

e-mail:Sarah.Bernays@lshtm.ac.uk

\section{Acknowledgements}

The authors wish to thank all the children and carers who participated in the ARROW social science sub-study for the time and information they shared with us. We are grateful to Hellen Nakyambadde, Olive Kabajaasi and Rachel Kawuma for data collection and their contributions to analysis. We thank the ARROW Train team for their support and the Department for International Development of the UK Government through the Medical Research Council (G0300400) for funding this study.

\section{References}

Abrahams, N. and Jewkes, R. (2012) Managing and resisting stigma: a qualitative study among people living with HIV in South Africa, Journal of the International AIDS Society, 15, 17330. doi.org/10. 7448/IAS.15.2.17330.

Andersen, L.B. (2012) Children's caregiving of HIV-infected parents accessing treatment in Western Kenya: Challenges and coping strategies, African Journal of AIDS Research, 11, 3, 203-13.

ARROW trial team, Kekitiinwa, A., Cook, A. and Nathoo, K. et al. (2013) Routine versus clinically driven laboratory monitoring and first-line antiretroviral therapy strategies in African children with HIV (ARROW): a 5-year open-label randomised factorial trial, Lancet, 381, 9875, 1391-403.

Berman, L. (2000) Surviving on the streets of Java: homeless children's narratives of violence, Discourse Society, 11, 2, 149-74.

Bernays, S., Rhodes, T. and Jankovic Terzic, K. (2010) You should be grateful to have medicines: continued dependence, altering stigma and the HIV treatment experience in Serbia, AIDS Care, 22, S1, $14-20$.

Bluebond-Langner, M. (1978) The Private Worlds of Dying Children. Princeton: Princeton University Press.

Bond, V. (2010) It is not an easy decision on HIV, especially in Zambia: opting for silence, limited disclosure and implicit understanding to retain a wider identity, AIDS Care, 22, S1, 6-13.

Busza, J., Besana, G.V., Mapunda, P. and Oliveras, E. (2013) I have grown up controlling myself a lot. Fear and misconceptions about sex among adolescents vertically-infected with HIV in Tanzania, Reproductive Health Matters, 21, 41, 87-96.

Campbell, C., Skovdal, M., Madanhire, C., Mugurungi, O. et al. (2011) We, the AIDS people: how antiretroviral therapy enables Zimbabweans living with HIV/AIDS to cope with stigma, American Journal of Public Health, 101, 6, 1004-10.

Castro, A. and Farmer, P. (2005) Understanding and addressing AIDS-related stigma: from anthropological theory to clinical practice in Haiti, American Journal of Public Health, 95, 1, 53-59.

Daniel, M., Apila, H.M., Bjørgo, R. and Lie, G.T. (2007) Breaching cultural silence: enhancing resilience among Ugandan orphans, African Journal of AIDS Research, 6, 2, 109-20.

Davies, M. (1997) Shattered assumptions: time and the experience of long-term HIV positivity, Social Science \& Medicine, 44, 5, 561-71.

Domek, G. (2006) Social consequences of antiretroviral therapy: preparing for the unexpected futures of HIV-positive children, The Lancet, 367, 9519, 1367-1369. 
Evans, R. and Becker, S. (2007) Hidden young carers: the experiences, needs and resilience of children caring for parents and relatives with HIVIAIDS in Tanzania and the UK: stakeholder report. Nottingham: School of Sociology and Social Policy, University of Nottingham.

Evans, R. and Becker, S. (2009) Children Caring for Parents with HIV and AIDS: Global Issues and Policy Responses. Bristol: Policy Press.

Ezekiel, M.J., Talle, A., Juma, J.M. and Klepp, K. (2009) When in the body, it makes you look fat and HIV negative: the constitution of antiretroviral therapy in local discourse among youth in Kahe, Social Science \& Medicine, 68, 5, 957-64.

Fielden, S., Chapman, G. and Cadell, S. (2011) Managing stigma in adolescent HIV: silence, secrets and sanctioned spaces, Culture, Health and Sexuality, 13, 3, 267-81.

Gilbert, L. and Walker, L. (2009) They (ARVs) are my life, without them I'm nothing - experiences of patients attending a HIV/AIDS clinic in Johannesburg, South Africa, Health and Place, 15, 4, 1123-9.

Goudge, J., Ngoma, B., Manderson, L. and Schneider, H. (2009) Stigma, identity and resistance among people living with HIV in South Africa, SAHARA, 6, 3, 94-104.

Hendry, J. and Watson, C. (2001) An Anthropology of Indirect Communication. London: Routledge.

Heymann, S., Clark, S. and Brewer, T. (2008) Moving from preventing HIV/AIDS in its infancy to preventing family illness and death (PFID), International Journal of Infectious Diseases, 12, 2, $117-19$.

Hunleth, J. (2013) ARVs as sickness and medicine: examining children's knowledge and experience in the HIV era in urban Zambia, AIDS Care, 25, 6, 763-6.

Hutchby, I. and Moran-Ellis, J. (1998) Children and Social Competence. London: Falmer.

Kia-Keating, M., Dowdy, E., Morgan, M.L. and Noam, G.G. (2011) Protecting and promoting: an integrative conceptual model for healthy development of adolescents, Journal of Adolescent Health, 48, 3, $220-8$.

Kirk, S. (2007) Methodological and ethical issues in conducting qualitative research with children and young people: a literature review, International Journal of Nursing Studies, 44, 7, 1250-60.

Kralik, D. (2002) The quest for ordinariness: transition experienced by midlife women living with chronic illness, Journal of Advanced Nursing, 39, 2, 391-400.

Luthar, S.S., Sawyer, J.A. and Brown, P.J. (2006) Conceptual issues in studies of resilience: past, present and future research, Annals of the New York Academy of Sciences, 1094, 105-15.

Maughan-Brown, B. (2010) Stigma rises despite antiretroviral roll-out: a longitudinal analysis in South Africa, Social Science \& Medicine, 70, 3, 368-74.

Mazanderani, F., Locock, L. and Powell, J. (2013) Biographical value: towards a conceptualisation of the commodification of illness narratives in contemporary healthcare, Sociology of Health \& Illness, 35, 6, 891-905.

Mellins, C. and Malee, K. (2013) Understanding the mental health of youth living with perinatal HIV infection: lessons learned and current challenges, Journal of International AIDS Society, 16, 1, 18593. doi.org/10.7448/IAS.16.1.18593.

Mishler, E.G. (2005) Patient stories, narratives of resistance and the ethics of human care: a la recherche du temps perdu, Health, 9, 4, 431-51.

Ochs, E. and Capps, L. (1996) Narrating the self, Annual Review of Anthropology, 25, 19-43.

Pols, J. (2005) Enacting appreciations: beyond the patient's perspective, Health Care Analysis, 13, 3, 203-21.

Prout, A. (2000) Children's participation: control and self-realisation in British late modernity, Children and Society, 14, 4, 304-15.

Prout, A. and James, A. (1990) Constructing and Reconstructing Childhood: Contemporary Issues in the Sociological Studies of Childhood. London: Falmer Press.

Robins, S. (2005) Rights passages from 'near death' to 'new life': AIDS activism and treatment testimonies in South Africa. IDS Working Paper 251. Brighton: Institute of Development Studies.

Russell, S. and Seeley, J. (2010) The transition to living with HIV as a chronic condition: working to create order and control on anti-retroviral therapy, Social Science \& Medicine, 70, 3, 375-82.

Seeley, J. and Russell, S. (2010) Social rebirth and social transformation? Rebuilding social lives after ART in rural Uganda, AIDS Care, 22, S1, 44-50. 
Shapiro, S., Angus, L. and Davis, C. (1997) Identity and meaning in the experience of cancer: three narrative themes, Journal of Health Psychology, 2, 4, 539-54.

Skovdal, M., Magutshwa-Zitha, S., Campbell, C. and Nyamukapa, C. et al. (2013) Children's role in the community response to HIV in Zimbabwe, Journal of the International AIDS Society, 16, 18468. doi.org/10.7448/IAS.16.1.18468.

Skovdal, M., Ogutu, V., Aoro, C. and Campbell, C. (2009) Young carers as social actors: coping strategies of children caring for ailing or ageing guardians in Western Kenya, Social Science \& Medicine, 69, 4, 587-95.

Thomas, C. (2013) Negotiating the contested terrain of narrative methods in illness contexts, Sociology of Health \& Illness, 32, 4, 647-60.

UNAIDS (2012) UNAIDS Report on the Global Aids Epidemic 2012. Available at http://www.unaids.org/ en/resources/publications/2012/name,76121,en.asp (accessed 16 July 2014).

Waitzkin, H. (1991) The Politics of Medical Encounters: How Patients and Doctors Deal with Social Problems. New Haven: Yale University Press.

Wekesa, E. and Coast, E. (2013) Living with HIV post diagnosis: a qualitative study of the experiences of Nairobi slum residents, BMJ Open, 3, 3, 5. e002399.

World Health Organization (2013) Global update on HIV treatment 2013: results, impact and opportunities. Geneva: WHO/UNAIDS.

Wilkinson, S.R. (1988) The Child's World of Illness: the Development of Health and Illness Behaviour. Cambridge: Cambridge University Press.

Williams, S.J. (2000) Chronic illness as biographical disruption or biographical disruption as chronic illness? Reflections on a core concept, Sociology of Health \& Illness, 22, 1, 40-67.

Wouters, E. (2012) Life with HIV as a chronic illness: a theoretical and methodological framework for antiretroviral treatment studies in resource-limited settings, Social Theory \& Health, 10, 368-91. doi:10.1057/sth.2012.12. 